\title{
In Vitro Generation of Early-Born Neurons from Late Retinal Progenitors
}

\author{
Jackson James, ${ }^{1}$ Ani V. Das, ${ }^{1}$ Sumitra Bhattacharya, ${ }^{1}$ David M. Chacko, ${ }^{2}$ Xing Zhao, ${ }^{1}$ and Iqbal Ahmad ${ }^{1}$ \\ ${ }^{1}$ Department of Ophthalmology, University of Nebraska Medical Center, Omaha, Nebraska 68198, and ${ }^{2}$ Grene Vision Group, Wichita, Kansas 67208
}

Evidence suggests that, as development ensues, the competence of neural progenitors is progressively altered, such that they become fated to give rise to neurons of a particular stage. Here, we demonstrate that late retinal progenitors can give rise to retinal ganglion cells (RGCs), an example of an early-born cell type in the retina. A subset of late retinal progenitors in vitro responds to cues that favor RGC differentiation by displaying markers characteristic of RGCs. In addition, mechanisms used during normal RGC differentiation are recruited by these cells toward their differentiation along RGC lineage. Our observations suggest that late neural progenitors may not be irreversibly fated but may appear as such under the constraints dictated by epigenetic cues.

Key words: retinal ganglion cells; Notch; stem cells/progenitors; differentiation; Ath5; Brn3b

\section{Introduction}

One of the central issues in neurobiology is the generation of cellular diversity in the CNS. The vertebrate retina is a simple and accessible model of the CNS suitable for investigating mechanisms underlying cellular diversity. The stereotypical laminar organization of retina consists of seven major cell types that include rod and cone photoreceptors, retinal ganglion cells (RGCs), horizontal cells, amacrine cells, bipolar cells, and Müller glia. Thymidine birth-dating studies have shown that the generation of these cells follows an evolutionarily conserved temporal sequence, in which RGCs, cone photoreceptors, horizontal cells, and the majority of amacrine cells are born during early histogenesis, whereas bipolar cells, Müller glia, and the majority of rod photoreceptors are born during late histogenesis (Sidman, 1961; Kahn, 1974; Young, 1985; LaVail et al., 1991; Prada et al., 1991). Despite overlaps in generation of certain cell types, the early and late stages of histogenesis are temporally segregated such that the majority of early and late-born neurons are generated approximately between embryonic day 10.5 (E10.5) and E16, and between E18 and postnatal day 6 (PN6), respectively, in the mouse retina (Sidman, 1961; Young, 1985; Robinson, 1991). Given the species difference in the gestation period, the majority of earlyborn neurons are believed to be generated between E11.5 and E17 in the rat retina (Robinson, 1991). Evidence from a variety of experimental approaches including cell ablation studies (Negishi et al., 1982; Reh and Tully, 1986) and lineage analyses (Turner and Cepko, 1987; Holt et al., 1988; Wetts and Fraser, 1988; Turner et al., 1990) suggest that the retinal progenitors are multipotential, and that the decision taken by a progenitor to differentiate along a particular path depends on local cell-cell interac-

Received April 29, 2003; revised July 2, 2003; accepted July 21, 2003.

This work was supported by the National Eye Institute, Nebraska Research Initiative, and Research to Prevent Blindness. We thank Dr. Jeremy Nathans for RPF1 antibody and Frank Soto Leon for his excellent technical assistance. Correspondence should be addressed to Dr. Iqbal Ahmad, Department of Ophthalmology, University of Nebraska Medical Center, 98-7691 Nebraska Medical Center, Omaha, NE 68198-7691. E-mail: iahmad@unmc.edu. Copyright $\odot 2003$ Society for Neuroscience $\quad$ 0270-6474/03/238193-11\$15.00/0 tions. In vitro coculture experiments, from different embryonic stages, offered additional proof that the differentiation of retinal progenitors can be influenced by epigenetic cues, and that these cues could be diffusible factors elaborated by previously differentiated cells and/or differentiating cells. The known diffusible factors that have been shown to affect differentiation of retinal progenitors include epidermal growth factor (EGF) (Anchan et al., 1991; Ahmad et al., 1998a), TGF $\alpha$ (Anchan et al., 1991; Lillien and Cepko, 1992), basic FGF (Hicks and Courtois, 1992), acidic FGF (Lillien and Cepko, 1992), taurine (Altshuler et al., 1993), CNTF (Kirsch et al., 1996; Ezzeddine et al., 1997), leukemia inhibitory factor (Neophytou et al., 1997), retinoic acid (Kelley et al., 1994), and sonic hedgehog (Levine et al., 1997; Zhang and Yang, 2001). There are yet-unidentified diffusible factors that have been shown to influence the differentiation of rods (Watanabe and Raff, 1990; Altshuler and Cepko, 1992; Harris and Messersmith, 1992; Reh, 1992; Watanabe and Raff, 1992; Belliveau et al., 2000), RGCs (Waid and McLoon, 1998), and amacrine cells (Belliveau and Cepko, 1999). Recent evidence suggests that, besides diffusible factors, cell-cell interactions mediated by membrane-bound receptors and ligand interactions, exemplified by Notch signaling, may play a critical role in retinal neurogenesis (Dorsky et al., 1995, 1997). Although it is still unclear how it achieves the specificity of cell fate determination, Notch signaling has been demonstrated to regulate both the temporal and spatial specification of retinal neurons, particularly RGCs (Ahmad, 1995; Austin et al., 1995; Ahmad et al., 1997).

Although these studies clearly demonstrate that the epigenetic cues play a critical role in differentiation of retinal progenitors, the conserved sequence of the generation of retinal cell types suggests that the progenitors that define the early and late stages of histogenesis have distinct competence to give rise to specific cell types. Additionally, evidence based on coculture studies suggests that the epigenetic cues work under the constraints of competence dictated by intrinsic factors. For example, early retinal progenitors, when cocultured with cells from the late stage of 
Table 1. List of primers and their respective sequences used for RT-PCR analysis

\begin{tabular}{|c|c|c|c|c|}
\hline Gene & Primer sequence & $\begin{array}{l}\text { Annealing } \\
\text { temperature }\end{array}$ & $\begin{array}{l}\text { Product } \\
\text { size (bp) }\end{array}$ & $\begin{array}{l}\text { GenBank acces- } \\
\text { sion number }\end{array}$ \\
\hline \multicolumn{5}{|l|}{$\beta$-actin } \\
\hline Forward & $5^{\prime}-$ GTGGGGCGCCCCAGGCACCA-3' & & & \\
\hline Reverse & 5'-CTCCTTAATGTCACGCACGATTTC-3' & $50^{\circ} \mathrm{C}$ & 543 & XM037235 \\
\hline \multicolumn{5}{|c|}{ (2) } \\
\hline Forward & 5'-TGCCTGGTGAACAGAACCTT-3' & & & \\
\hline Reverse & $5^{\prime}-$ TCACAGAGAAATGAAGTCCGTGGC-3' & $58^{\circ} \mathrm{C}$ & 415 & NM_012673 \\
\hline \multicolumn{5}{|c|}{ 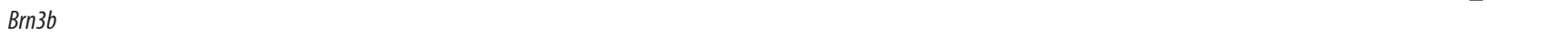 } \\
\hline Forward & $5^{\prime}$-GGCTGGAGGAAGCAGAGAAATC-3' & & & \\
\hline Reverse & $5^{\prime}-$ TTGGCTGGATGGCGAAGTAG-3' & $60^{\circ} \mathrm{C}$ & 141 & AF390076 \\
\hline \multicolumn{5}{|c|}{ 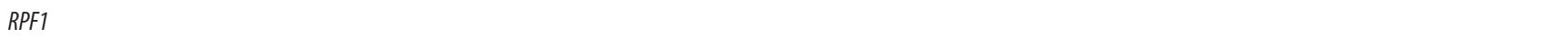 } \\
\hline Forward & $5^{\prime}-$ CTCATTCCCTTCAACATG-3' & & & \\
\hline Reverse & $5^{\prime}-$ TGGTTGGTTCTGGTTGTG-3' & $54^{\circ} \mathrm{C}$ & 426 & XM_011564 \\
\hline \multicolumn{5}{|l|}{ Islet1 } \\
\hline Forward & 5'-CTGATTTCCCTATGTGTTGGTTGC-3' & & & \\
\hline Reverse & 5'-TTCTTGCTGAAGCCTATGCTGC-3' & $54^{\circ} \mathrm{C}$ & 230 & NM_017339 \\
\hline \multicolumn{5}{|c|}{ - } \\
\hline Forward & $5^{\prime}$-CATGCAGTGTTCATGTGGGA-3' & & & \\
\hline Reverse & 5'-AGCAGAGGCTGGTGAGCATG-3' & $64^{\circ} \mathrm{C}$ & 382 & U22180 \\
\hline \multicolumn{5}{|l|}{ Ath5 } \\
\hline Forward & $5^{\prime}-\mathrm{TGGGG}(\mathrm{I}) \mathrm{CA}(\mathrm{GA}) \mathrm{GA}(\mathrm{CT}) \mathrm{AA}(\mathrm{GA}) \mathrm{AA}(\mathrm{GA})-3^{\prime}$ & & & \\
\hline Reverse & $5^{\prime}-\mathrm{CAT}$ (I) GG (GA) AA (I) GG (CT) TC (I) GG (CT) TG-3' & $52^{\circ} \mathrm{C}$ & 231 & AF071223 \\
\hline \multicolumn{5}{|c|}{ (2) } \\
\hline Forward & $5^{\prime}-$ TCTGGACAAGATTGATGGCTACG-3' & & & \\
\hline Reverse & 5'-CGTTGACACAAGGGTTGGACTC-3' & $56^{\circ} \mathrm{C}$ & 329 & NM_008714 \\
\hline \multicolumn{5}{|l|}{ Hes1 } \\
\hline Forward & 5'-GCTTTCCTCATCCCCAATG-3' & & & \\
\hline Reverse & 5'-CGTATTTAGTGTCCGTCAGAAGAG-3' & $56^{\circ} \mathrm{C}$ & 224 & NM_024360 \\
\hline \multicolumn{5}{|c|}{ 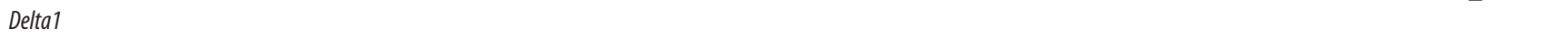 } \\
\hline Forward & $5^{\prime}-$ CGACCTCGCAACAGAAAAC-3' & & & \\
\hline Reverse & 5'-ATGGAGACAGCCTGGGTATC-3' & $56^{\circ} \mathrm{C}$ & 397 & NM_032063 \\
\hline
\end{tabular}

histogenesis, failed to give rise to late-born retinal cells (Morrow et al., 1998; Belliveau and Cepko, 1999; Rapaport et al., 2001), and conversely, late retinal progenitors failed to generate early-born retinal neurons when cultured with cells from the late stage of histogenesis (Morrow et al., 1998). Recent studies suggest that intrinsic factors that may regulate the competence of stagespecific progenitor and precursor populations belongs to the basic helix-loop-helix (bHLH) class of transcription factors such as Mash1 (Ahmad, 1995; Jasoni and Reh, 1996; Kageyama et al., 1997; Ahmad et al., 1998a), Xash1 and Xash3 (Kanekar et al., 1997), Ngn2 (neurogenin 2) (Sommer et al., 1996), Ath5 (Kanekar et al., 1997; Brown et al., 2001), Ath3 (Kageyama et al., 1997; Roztocil et al., 1997; Tsuda et al., 1998), Ath6 (Bae et al., 2000), and NeuroD (Ahmad et al., 1998b; Morrow et al., 1999).

Here, we demonstrate that the change in the competence of retinal progenitors during development may not be irreversible and can be influenced by epigenetic cues in vitro. We observed that a subset of enriched late retinal progenitors, when shifted to differentiation condition, expressed RGC-specific markers, suggesting their potential to give rise to early-born neurons. Exposure of these progenitors to a condition that is conducive for RGC differentiation, such as coculturing them with retinal cells from a stage representing the peak of RGC genesis, doubled the number of cells expressing RGC-specific markers, suggesting that a subset of late retinal progenitor is competent to respond to cues that promote RGC differentiation. The acquisition of RGC phenotype by late retinal progenitors involved Notch signaling and was preceded by and/or accompanied with the expression of two known regulators of RGC differentiation, Ath5 and Brn3b. Our results suggest that a subset of late retinal progenitors is competent to generate early-born neurons and mechanisms that are used in vivo are recruited by these cells to differentiate into RGCs in vitro.

\section{Materials and Methods}

Progenitor cell culture. Timed-pregnant (E18) Sprague Dawley rats were obtained from Sasco (Wilmington, MA). The gestation day was confirmed by the morphological examination of embryos (Christie, 1964). Fertilized hen eggs (SPAFAS, Wilmington, MA) were incubated in a humidified chamber at $38^{\circ} \mathrm{C}$, and embryos were staged according to Hamburger and Hamilton (1951). Embryos were harvested at appropriate gestation periods, and eyes were enucleated. Retinas were dissected out and dissociated as previously described (Ahmad et al., 1999). Cells were plated in six-well culture plates at a density of $2 \times 10^{6}$ cells/well in DMEM:F12, $1 \times$ N2 supplement (Invitrogen, San Diego, CA), 2 mM L-glutamine, $100 \mathrm{U} / \mathrm{ml}$ penicillin, $100 \mu \mathrm{g} / \mathrm{ml}$ streptomycin, and $20 \mathrm{ng} / \mathrm{ml}$ EGF for $5 \mathrm{~d}$ to generate clonal neurospheres. 5-Bromo-2'-deoxyuridine (BrdU) $(10 \mu \mathrm{M})$ was added to the culture for the final $24 \mathrm{hr}$. The next day, neurospheres were collected, washed extensively to remove BrdU, and cocultured on poly-D-lysine- and laminin-coated glass coverslips with E3 chick retina/PN1 rat retinal cells in 1\% FBS. E18 rat retinal cells cultured in $1 \%$ FBS or cocultured with E3 chick or PN1 rat cerebral cortex served as controls. For RT-PCR analysis of transcripts expressed in E18 rat retinal cells, coculture was performed across a $0.4 \mu \mathrm{m}$ membrane (Millipore, Bedford, MA). The medium was changed every other day, and culture was continued for 5-6 d. Cells were either frozen for RNA extraction or fixed with $4 \%$ paraformaldehyde for $15 \mathrm{~min}$ at $4^{\circ} \mathrm{C}$ followed by immunofluorescence analysis.

RGC birth dating. E18 and PN1 rats were injected with BrdU (120 $\mathrm{mg} / \mathrm{kg}$ of body weight) intraperitoneally before being killed at birth and PN6, respectively (Ahmad et al., 1998a). The eyes were enucleated and fixed, and 10-12 $\mu \mathrm{m}$ cryosections were obtained from each eye. Double- 

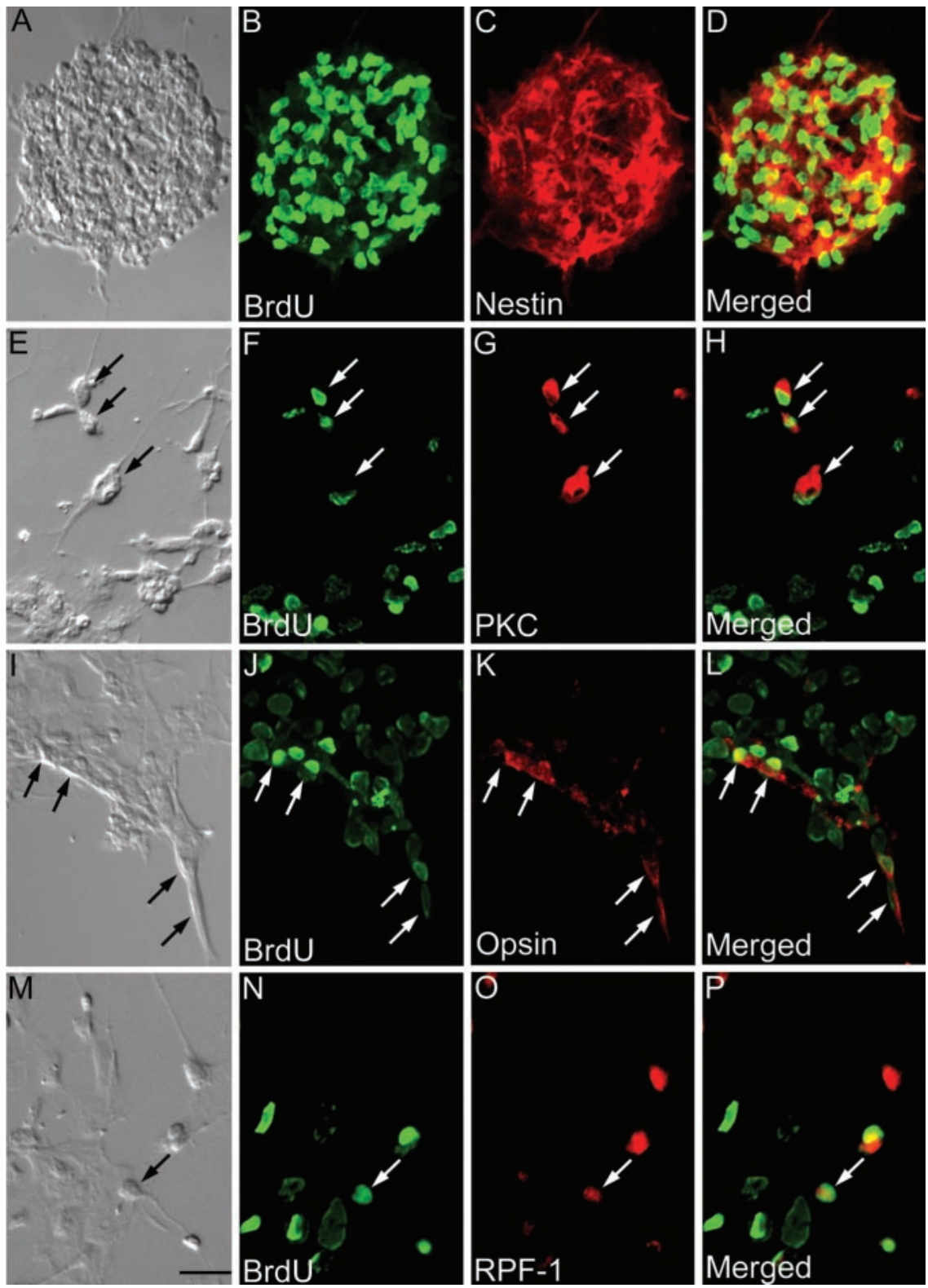

Figure 1. Cultured retinal progenitors express late-born neuron- and RGC-specific markers. E18 retinal cells were cultured in the presence of EGF to enrich retinal progenitors as neurospheric cells that incorporated BrdU and expressed Nestin $(A-D)$. Substitution of mitogen with $1 \%$ FBS led neurospheric cells to express PKC ( $E-H$, arrows) and opsin (I-L, arrows), markers that characterize late-born neurons, bipolar cells, and rod photoreceptors, respectively. A small subset of cells (arrow) was observed in the presence of FBS that expressed RPF1, a marker expressed by early-born neurons, RGCS (M-P). Scale bar, $100 \mu \mathrm{m}$.

immunochistochemical analysis was performed to detect cells expressing BrdU and RGC-specific markers.

Hoechst dye efflux assay. The progenitor and precursors in E18 neurospheres cultured in E3 conditioned medium were enriched using a Hoechst dye efflux assay (Bhattacharya et al., 2003). Briefly, dissociated cells were resuspended in Hoechst Iscove's modified Dulbecco's medium $\left(10^{6}\right.$ cells $\left./ \mathrm{ml}\right)$ containing $2 \% \mathrm{FCS}$ at $4^{\circ} \mathrm{C}$ overnight followed by staining with Hoechst $33342(2 \mu \mathrm{g} / \mathrm{ml})$ at $37^{\circ} \mathrm{C}$ for $30 \mathrm{~min}$ and sorted on a FACStar ${ }^{\text {Plus }}$ (BD Biosciences, Lincoln Park, NJ) cell sorter. Hoechst dye was excited at $350 \mathrm{~nm}$, and fluorescence was measured at two wavelengths using a 485 BP22 (485 nm bandpass filter) and a 675 EFLP (675 nm long-pass edge filter) optical filter (Omega Optical, Brattleboro, VT). The side-population (SP) region was defined on the cytometer on the basis of its fluorescence emission in both blue and red wavelengths. Dead cells and debris were excluded by establishing a live gate on the flow cytometer using forward versus side scatter. The sorted SP and non-SP (NSP) cells were centrifuged and used for RT-PCR analysis.
Immunofluorescence analysis. Detection of cellspecific markers and BrdU was performed as previously described (Ahmad et al., 1999). Briefly, paraformaldehyde-fixed cells were incubated in PBS containing 5\% NGS and $0.2-0.4 \%$ Triton $\mathrm{X}-100$ followed by an overnight incubation in antibodies against rhodopsin, PKC, Nestin RPF1, Islet1, Brn3b, Thy1, and BrdU at $4^{\circ} \mathrm{C}$. Cells were examined for epifluorescence after incubation in IgG conjugated to cyanin 3 (Cy3)/FITC. Images were captured using a cooled CCD camera (Princeton Instruments, Trenton, NJ) and Openlab software (Improvision, Lexington, MA)

$R T-P C R$ analysis. RNA was isolated from frozen cells using a Qiagen (Valencia, CA) RNA isolation kit, and CDNA synthesis was performed as previously described (Bhattacharya et al., 2003) Specific transcripts were amplified with genespecific forward and reverse primers on a Robocycler (Stratagene, La Jolla, CA). The genespecific primers used for RT-PCR are described in Table 1.

Transplantation of E18 retinal progenitors. E18 retinal cells were obtained from green fluorescent protein (GFP)-expressing transgenic mice (Okabe et al., 1997) and cultured to obtain GFPpositive neurospheres as described above. Transplantation of GFP-positive retinal progenitors was performed in $\mathrm{PN} 10 \mathrm{P} 23 \mathrm{H}$ transgenic rats containing the proline-23-histidine (Pro ${ }^{23} \mathrm{His}$ ) rhodopsin mutation [line $\operatorname{TgN}(\mathrm{P} 23 \mathrm{H}) 3$ ] as previously described (Lewin et al., 1998; Chacko et al., 2003). Animals were anesthetized with 20-25 $\mu \mathrm{l}$ of a 1:1 dilution of ketamine $(60 \mathrm{mg} / \mathrm{ml})$ and xylazine $(8 \mathrm{ng} / \mathrm{ml})$, injected intraperitoneally. A 30 -gauge needle was inserted into the eye near the equator. The needle was retracted, and a glass micropipette connected to a $10 \mu \mathrm{l}$ Hamilton syringe was inserted through the wound to deliver 50,000 cells in a $1 \mu \mathrm{l}$ volume. Animals were in jected with cyclosporin $\left(5 \mathrm{mg} \cdot \mathrm{kg}^{-1} \cdot \mathrm{d}^{-1}\right)$ and killed at 1,2, and 3 weeks after transplantation. Eyes were enucleated and processed for immunohistochemical analysis.

\section{Results}

\section{A subset of late retinal progenitors} expresses RGC-specific markers in vitro E18 retinal progenitors normally generate rod photoreceptors, bipolar cells, Müller glia, and a subset of amacrine cells. It has been observed that these progenitors have intrinsic limitations regarding the range of cell types that they can generate (Belliveau et al., 2000). To investigate the extent of plasticity of late retinal progenitors, E18 retinal dissociates were cultured in the presence of EGF. In this culture condition, progenitors are selectively amplified, giving rise to neurospheres that consist of Nestin-positive proliferating cells (Fig. 1A-D). E18 retinal progenitors, thus enriched and tagged with BrdU, were allowed to differentiate by substituting FBS for mitogens in the culture medium. As expected, BrdU-positive cells that expressed rhodopsin and PKC were observed, suggesting the differentiation of progenitors into late-born neurons, rod photoreceptors, and bipolar cells, respectively (Fig. $1 E-L$ ). To determine the plasticity of the retinal progenitors in terms of generating early-born neurons, expression of markers characteristic of differentiating RGCs were analyzed. These include RPF1, a member of VI POU 
domain subfamily, which is one of the earliest RGC differentiation markers, detected as early as E11 in the mouse retina (Zhou et al., 1996). Islet1, a member of homeodomain family, is another early RGC marker (Rachel et al., 2002). BrdUpositive cells were detected that expressed RPF1, suggesting that a subset of E18 retinal progenitors may possess the capacity to differentiate along RGC lineage (Fig. $1 \mathrm{M}-$ $P)$. Similar immunocytochemical results were obtained using antibody against Islet1 (data not shown).

\section{Cells from an early stage of retinal} histogenesis facilitate differentiation of late retinal progenitors into RGCs Next, we wanted to know whether the potential of cultured E18 retinal progenitors can be influenced by epigenetic cues, because evidence has emerged that cell-cell interaction plays a critical role in the specification of retinal progenitors (Cepko, 1999). The differentiation of E18 retinal progenitors was analyzed in cultured conditions that are conducive for the differentiation of early-born neurons. BrdUtagged E18 retinal progenitors were cocultured with an excess of E3 chick retinal dissociates. Several factors were considered for choosing E3 chick retinal cells for inducing RGC differentiation. First, stages E3-E5 in chick retina represent the peak of RGC genesis (Prada et al., 1991). Second, it is likely that the cues that influence RGC differentiation are evolutionarily conserved, because, regardless of species, RGCs are the first retinal cell types to differentiate. Therefore, rat retinal progenitors may be able to read out cues for RGC differentiation elaborated by E3 chick retinal cells. Third, more cells can be harvested with relative ease from E3 chick retina than from E13-E14 rat retina, the peak of RGC genesis. When E18 retinal progenitors were cultured with E3 chick retinal cells, the proportion of BrdU-positive cells expressing RGC markers increased compared with controls. In the presence of FBS, $18.70 \pm 1.22$ and $10.17 \pm 1.00 \%$ of BrdU-positive cells expressed RPF1 and Islet 1 , respectively. In the presence of E3 chick cerebral cortex cells, $15.3 \pm 1.90$ and $6.5 \pm 0.50 \%$ of BrdU-positive cells expressed RPF1 and Islet1, respectively (Fig. 2). In contrast, the proportion of BrdU-positive cells expressing RGC markers increased significantly when cocultured with E3 chick retinal cells; $32.53 \pm 1.98$ and $34.70 \pm 1.90 \%$ of BrdU-positive cells expressed RPF1 and Islet1, respectively, suggesting a positive influence of E3 chick retinal cells on RGC differentiation (Fig. $2 A-D, I$ ). Three different approaches were taken to corroborate the plasticity of late retinal progenitors to generate RGCs. First, we investigated their ability to express Brn3b, which is a member of the pou domain subfamily and expressed in a large subpopulation $(\sim 70 \%)$ of differentiating and matured RGCs (Xiang et al., 1993; Gan et al., $1996,1999)$. In the presence of FBS, $9.12 \pm 1.52 \%$ of BrdU-
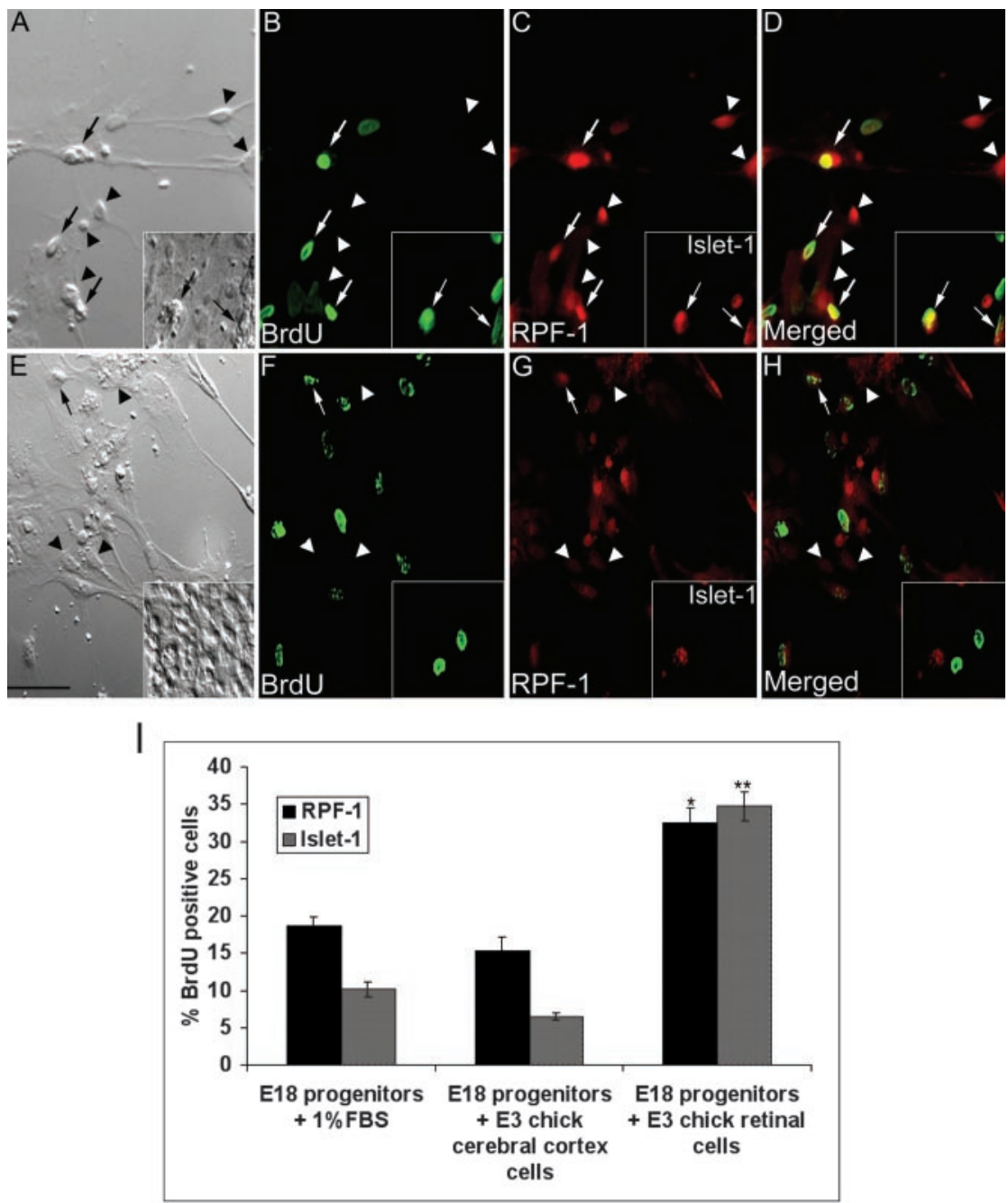

Figure 2. Differentiation of the late retinal progenitor into RGC is influenced by factor(s) elaborated by cells representing the early ans) expressed RGC-specific markers, RPF1 and Islet1 (inset), in the presence of E3 chick retinal cells ( $A-D$, arrowhead) than in the 作 separate observations, as assessed by one-way ANOVA. Scale bar, $100 \mu \mathrm{m}$.

positive cells expressed Brn3b. In contrast, $24.48 \pm 1.88 \%$ of BrdU-positive cells expressed Brn3b when cocultured with E3 chick retinal cells, a significant increase similar to those observed for RPF1 and Islet1 in coculture conditions (Fig. 3). Second, we performed coculture across a $0.4 \mu \mathrm{m}$ membrane to corroborate results by analyzing the expression of transcripts corresponding to RGC markers. RT-PCR analysis performed on late retinal progenitors identified the expression of transcripts corresponding to Islet 1, RPF1, Brn3b, and Thy1 whose levels increased in the presence of E3 chick retinal cells, suggesting that RGC-specific genes are activated by epigenetic cues, and that these cues are likely to be diffusible (Fig. 4A). Third, we cultured late retinal progenitors in E3 chick-conditioned medium to further confirm their differentiation along RGC lineage by colocalization of different RGC differentiation markers. Double-immunocytochemical analysis revealed that a subset of cells coexpressed Islet1 and RPF1 (Fig. $4 B-E) / \operatorname{Brn} 3 \mathrm{~b}(F-I)$, suggesting that late retinal progenitors possess the ability to express multiple markers of RGC differentiation 

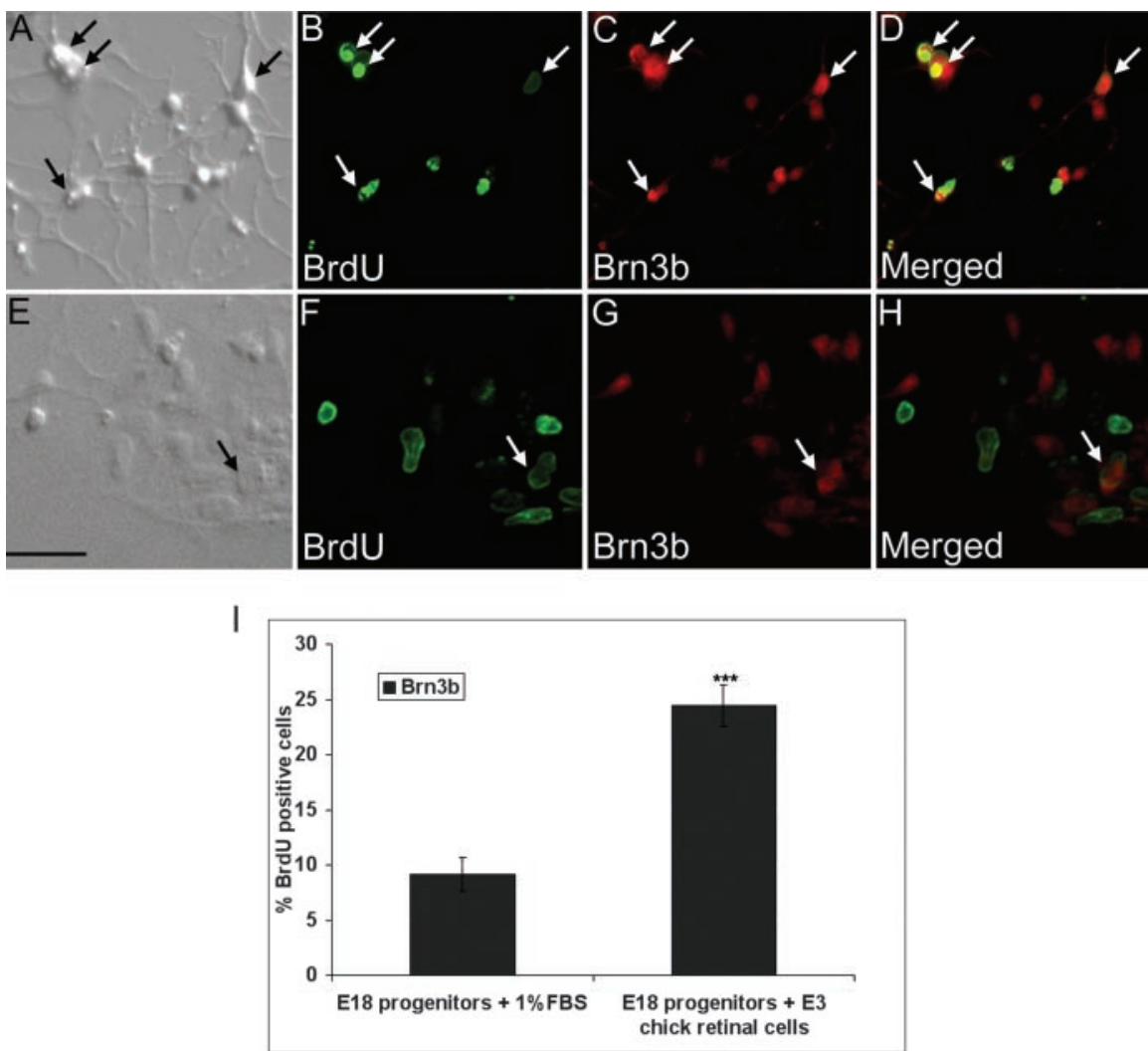

Figure 3. Late retinal progenitors cocultured with $\mathrm{E} 3$ chick retinal dissociates express $\mathrm{RGC}$-specific marker Brn3b. Late retinal progenitors tagged with BrdU were cocultured with $\mathrm{E} 3$ chick retinal dissociates $(A-D)$. For controls, BrdU-tagged cells were cultured in the presence of $1 \% \mathrm{FBS}(E-H)$. BrdU-tagged late retinal progenitors cocultured with $\mathrm{E} 3$ chick retinal cells expressed the RGC-specific marker Brn3b in a higher proportion compared with control. Graph (I) depicts significant increase in Brn3b under coculture condition compared with control $\left({ }^{* *} p<0.001\right)$. Values are means \pm SEM of four to six separate observations, as assessed by Student's $t$ test. Scale bar, $100 \mu \mathrm{m}$.

in coculture condition. To ascertain that cues promoting RGC differentiation are not species specific, BrdU-tagged late retinal progenitors were cocultured with E14 rat retinal cells. The proportion of BrdU-positive cells expressing RGC-specific markers increased significantly compared with controls, suggesting that factors that participate in RGC differentiation during early histogenesis are conserved across species (Fig. 5A-D,I).

\section{Cells from an early stage of retinal histogenesis inhibit differentiation of late retinal progenitors into rod photoreceptors}

To determine whether E3 chick retinal cells influence the differentiation of late retinal progenitors into late-born neurons such as rod photoreceptors, expression of rhodopsin was analyzed in BrdU-tagged late retinal progenitors after coculture. A significant decrease in the proportion of BrdU-positive cells expressing opsin was observed in the presence of E3 chick retinal cells compared with control $(23.24 \pm 1.92$ vs $15.3 \pm 2.52 \%$; $p<0.01)$, suggesting that the presence of cells from early stages of retinal histogenesis compromises the differentiation of late-born neurons (Fig. 6A). A negative effect on rod photoreceptor differentiation was also induced by cells from the cerebral cortex, as ascertained by a relative decrease in the levels of opsin transcripts (Fig. $6 B$ ). However, to rule out an alternative possibility that the negative influence of $\mathrm{E} 3$ chick retinal cells on rod photoreceptor differentiation does not reflect an altered potential of E18 retinal progenitors in vitro, we cocultured these cells in the presence of postnatal retinal cells that have been observed to secrete factors that promote rod photoreceptor differentiation (Altshuler and Cepko, 1992; Watanabe and Raff, 1992; Ahmad et al., 1999). The presence of postnatal retinal cells significantly increased the proportion of opsin-positive cells and levels of opsin transcripts compared with controls, suggesting that E18 progenitors maintain their normal potential to differentiate into rod photoreceptors in response to conducive conditions (Fig. 6).

\section{The RGC potential is inherent to a subset of late retinal progenitors and is constrained in vivo}

Although the majority of RGCs are born between E11.5 and E17, a few of these cells are reported to be generated in the peripheral E18 retina (Reese and Colello, 1992). Therefore, it is probable that RGCs generated in vitro are derived from few residual early progenitors. We addressed this issue in two different ways. First, we determined whether, as in Long-Evans (pigmented) rats (Reese and Colello, 1992), RGCs are born in the E18 retina of Sprague Dawley (albino) rats. Pregnant rats at day 18 of gestation were injected with $\mathrm{BrdU}$, and eyes were enucleated from $\mathrm{PN} 1$ pups for immunohistochemical analysis of the retina. Although BrdU-positive cells were readily observed, none of these cells expressed RGC-specific markers, either in the central or peripheral retina (Fig. $7 A-$ $P$ ), suggesting that, in Sprague Dawley rats, RGC genesis is complete by E18; and therefore, our observation of RGC generation in vitro is unlikely to be attributable to residual early progenitors. The difference in the genesis of RGCs between Long-Evans and Sprague Dawley is likely attributable to albinism; it has been demonstrated recently that the temporal aspects of RGC genesis is different between albino and wild-type mice, being completed earlier in the former than in the latter (Rachel et al., 2002). Second, we performed RGC birth dating in PN1 rats and investigated the potential of PN1 retinal progenitors to differentiate into RGCs. This experiment was performed to address the concern that, regardless of species difference, we might have overlooked a small number of RGCs generated in the peripheral retina at E18 or staged the gestation day of pregnant rats incorrectly. Similar to our observations in the E18 retina, we did not detect proliferating cells in the PN1 retina that expressed RGC-specific markers (data not shown). As observed for late progenitors derived from the E18 retina, PN1 retinal progenitors differentiated into RGCs; the proportion of RGCs generated was higher in coculture condition than in the control (Islet1, $5.57 \pm 0.99$ vs $11.53 \pm 2.74 \%$; RPF1, $13.52 \pm 1.91$ vs $23.26 \pm 1.66 \%)$. Similar results were obtained with PN3 retinal progenitors. However, there was a progressive decrease in the proportion of cells expressing RGC markers in coculture condition at each subsequent time point (Fig. 7Q). Together, these observations suggest that a subset of retinal progenitors derived from the postnatal retina possess the potential to give rise to early-born neurons, and that they are depleted as 
histogenesis progresses toward completion. Next, we wanted to know whether RGC potential of late retinal progenitors are inherent or acquired de novo because of prolonged exposure to mitogens during the enrichment process. We analyzed the potential of freshly dissociated late retinal progenitors to generate RGCs without being exposed to mitogens. Pregnant rats were injected with BrdU to tag the progenitors in vivo. E18 retinal cells were harvested, an aliquot of cells was processed directly for immunocytochemical analysis, and the rest were cocultured with E3 chick retinal cells for $5 \mathrm{~d}$. BrdU-tagged neurospheric cells were used as control; cell dissociates from mitogen-exposed neurospheres were cultured in the presence of $1 \%$ FBS for $5 \mathrm{~d}$ before immunocytochemical analysis. In E18 retinal dissociates that were analyzed immediately after harvest, BrdU-positive cells expressing RGC markers were not observed, suggesting that late retinal progenitors do not give rise to RGCs in vivo (data not shown). However, when freshly dissociated E18 retinal progenitors were cocultured with E3 chick retinal cells, a small proportion of BrdU-positive cells was observed that expressed RPF1 (3.09 $\pm 0.30 \%)$ and Islet1 $(5.2 \pm 0.53 \%)$, suggesting that a subset of late retinal progenitors may possess the potential to give rise to RGCs but are constrained in vivo, and that the culture condition promotes this potential (Fig. $8 \mathrm{~A}$ ). In contrast, a higher proportion of cells obtained from neurospheres expressed RPF1 (18.70 $\pm 1.22 \%)$ and Islet1 $(10.17 \pm 1.00 \%)$, suggesting that the subset of late retinal progenitors that possess the potential to generate RGCs is amplified during the enrichment process involving mitogens. To investigate further, if the in vivo environment has a negative influence on the ability of late retinal progenitors to generate early-born neurons, enriched late retinal progenitors were transplanted intravitreally into a 10 - $\mathrm{d}$-old rat pup containing the $\mathrm{P} 23 \mathrm{H}$ mutation in the opsin gene that leads to retinal degeneration. We showed that retinas containing genetic or traumatic injury promote incorporation of grafted cells in the laminar structure (Chacko et al., 2003). Grafted progenitors were observed in the retina that expressed RPF1, suggesting their differentiation along RGC lineage (Fig. 8B-F). However, the proportion of cells that expressed RPF1 was significantly less than those in vitro $(0.13$ vs $20 \% ; p<0.001)$, suggesting that late retinal progenitors are constrained from differentiating into RGC in vivo.

\section{Differentiation of late retinal progenitors into RGCs involves Notch signaling}

Several lines of evidence suggest that Notch signaling is involved in the specification of RGCs. First, both the Notch1 receptor and its ligand Delta1 are expressed during the genesis of RGCs (Ahmad et al., 1995, 1997), and second, functional analyses of Notch1 and Delta1 have demonstrated that the temporal and spatial specification of RGCs is regulated by Notch signaling (Austin et al., 1995; Ahmad et al., 1997). We were interested in knowing whether the differentiation of late retinal progenitors into RGCs in vitro involves Notch signaling. Levels of transcripts
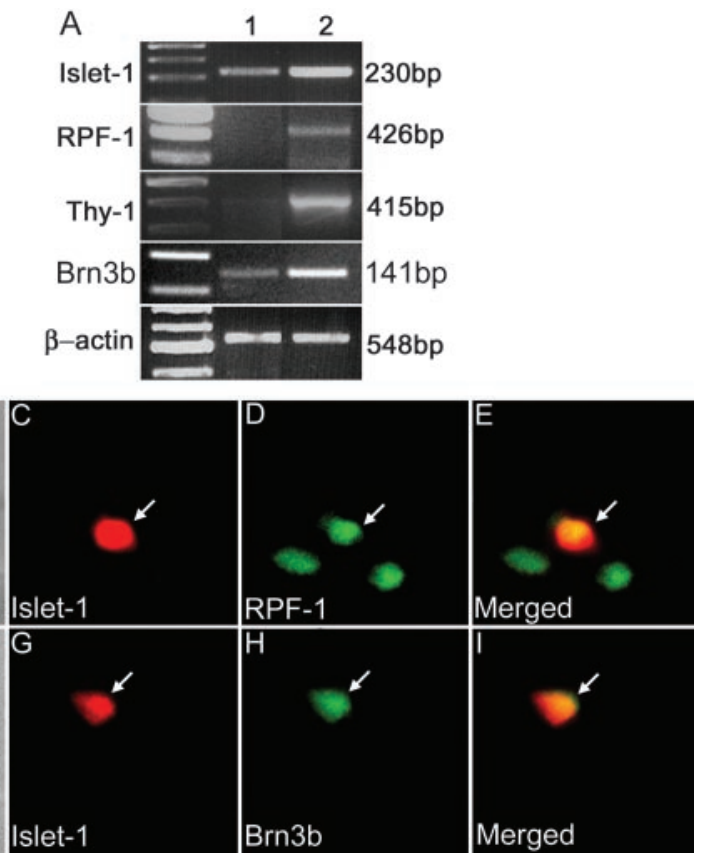

Figure 4. Diffusible factors secreted by E3 chick retinal dissociate influence late retinal progenitors to express multiple RGC specific transcripts. Immunocytochemical results were corroborated by RT-PCR analysis in late retinal progenitors $(A)$. The levels 2) compared with those cultured in the presence of $1 \%$ FBS (lane 1). Culture of late retinal progenitors with E3 chick-conditioned medium influenced late retinal progenitors to coexpress multiple RGC markers such as Islet1 and RPF1 ( $B-E$, arrow), and Islet1 and

corresponding to Notch1 and Delta1 were analyzed in late retinal progenitors, cultured either in the presence of FBS or E3 chick retinal cells. In addition, we analyzed levels of Ath5 and Brn $3 b$ mRNA. Ath5, a bHLH transcription factor, is required for the genesis of RGCs (Brown et al., 2001) and regulates Brn3b, a POU domain transcription factor, expressed during early differentiation of RGCs (Xiang et al., 1993; Gan et al., 1996, 1999). The levels of Notch1 and Delta1 transcripts were observed to be increased in E18 retinal progenitors in coculture condition compared with those of the FBS control, suggesting that Notch signaling is enhanced during their differentiation into RGCs (Fig. 9A,B). There was a corresponding increase in the levels of Ath 5 and Brn3b transcripts that, together with the observation of an increase in Notch signaling, suggests that mechanisms involved in the genesis of RGCs in vivo are recruited by late retinal progenitors during their differentiation into RGCs in vitro. Evidence suggests that, during RGC differentiation, there is a relative increase in Notch signaling in progenitors: first, to maintain their uncommitted state, and second, to accentuate their difference from differentiating precursors (Ahmad et al., 1997). To test this notion in the context of differentiation of late retinal progenitors into RGCs, progenitors and postmitotic precursor populations were isolated using the Hoechst dye efflux assay (Bhattacharya et al., 2003). This assay separates the two populations on the basis of their relative ability to exclude the Hoechst dye; retinal progenitors that exclude the dye constitute the SP, whereas postmitotic precursors and differentiated cells with relative inability to exclude the dye form the NSP (Fig. 9C). The levels of Notch signaling in these two populations were evaluated by measuring levels of transcripts corresponding to Notch1, Delta1, and Hes1, a transcriptional repressor activated in response to Notch signaling (Fig. 9D). Whereas transcripts corresponding to Notch1, Delta1, and Hes 1 are expressed in the SP cells, those corresponding to Delta1 

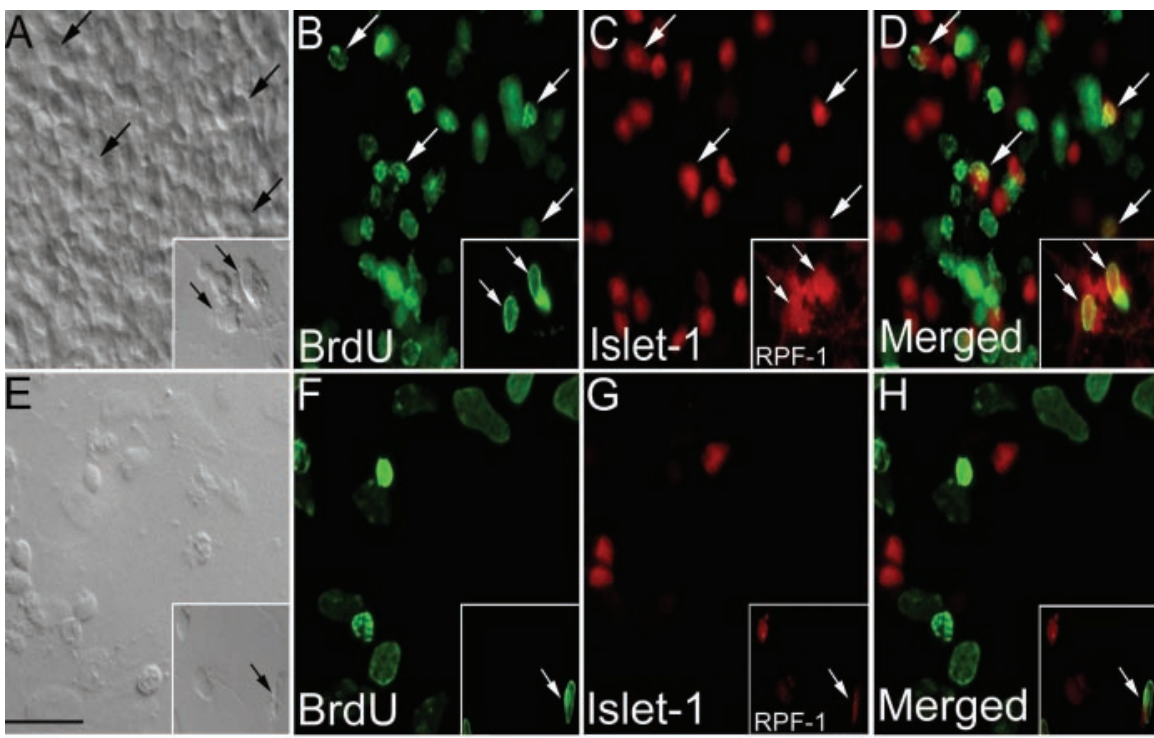

I

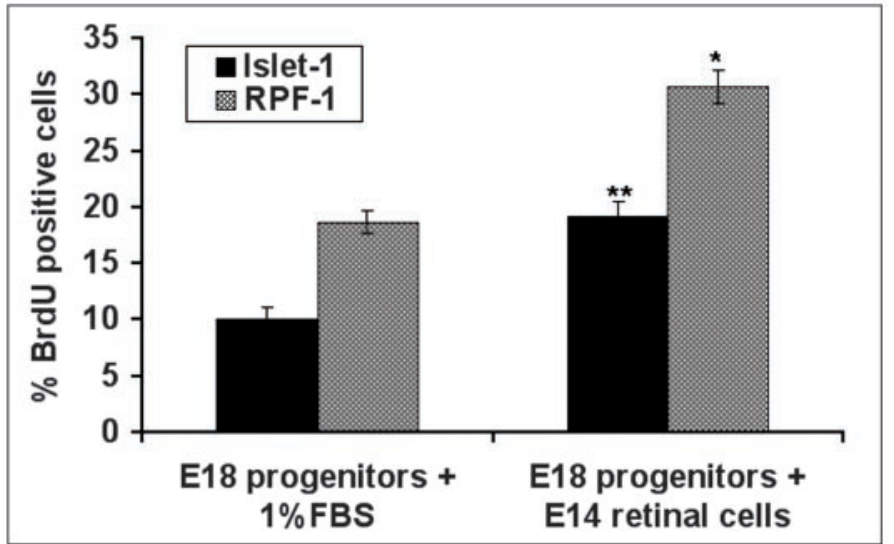

Figure 5. Factors that promote differentiation of late retinal progenitors into RGCs are evolutionarily conserved. To determine the conserved nature of the epigenetic cues that promote RGC differentiation, BrdU-tagged late retinal progenitors were cocultured with rat retinal cells from the E14 stage of RGC genesis. Control included culturing progenitors in the presence of $1 \%$ FBS. More BrdU-tagged late retinal progenitors (arrows) expressed Islet1 and RPF1 (inset) in the presence of E14 retinal cells $(A-D)$ than in the control $(E-H)$. The graph $(I)$ shows that the proportion of late retinal progenitors expressing Islet1 and RPF1 increased more significantly in the presence of E14 rat retinal cells than in the control (**Islet1, $\left.p<0.01 ;{ }^{*} \mathrm{RPF1}, p<0.05\right)$, suggesting that RGC-promoting factors are conserved between chick and rat. Values are means \pm SEM of four to six separate observations, as assessed by Student's $t$ test. Scale bar, $100 \mu \mathrm{m}$.

are detectable in the NSP cells, suggesting that Notch signaling is relatively enhanced in the progenitor population, presumably to maintain the progenitor population and promote gradual differentiation between progenitors and precursors that have decided to become RGCs.

\section{Discussion}

In the retina, neurons belonging to specific types are born in two distinct stages of histogenesis in a lineage-independent manner. The temporal segregation in the generation of different types of neurons indicates that progenitors that define early and late stages of histogenesis are intrinsically different (i.e., they have distinct competence to respond to stage-specific epigenetic cues). This notion presupposes that, as development proceeds, progenitors progressively express different combination of genes that allow them to read epigenetic cues of a particular stage, and it is this communication between cell-intrinsic and cell-extrinsic factors that ultimately specifies the fate of a progenitor at a given stage. Consequently, early retinal progenitors are incompetent to give rise to lateborn neurons even when exposed to an environment that promotes generation of the latter (Morrow et al., 1998; Belliveau and Cepko, 1999; Rapaport et al., 2001) and vice versa (Belliveau et al., 2000). A similar developmental constraint on progenitors to give rise to specific neuronal types has been observed in the cerebral cortex, in which cells of different cortical layers are generated in an inside-out manner, in a strict temporal sequence (O'Rourke et al., 1995). As in the developing retina, the late cortical progenitors fated to become neurons of superficial layers were found to be incompetent to generate early-born deep-layer neurons when transplanted in younger ferret hosts (Frantz and McConnell, 1996).

The observations from the retina and cerebral cortex suggest that the competence of the retinal progenitor changes irreversibly as development ensues. Alternatively, the change in competence may not be irreversible, but progenitors are constrained by overwhelming epigenetic influence from giving rise to any other neuronal types than those born during that particular stage. To test this notion, we investigated the ability of enriched late retinal progenitors to give rise to early-born neurons, specifically RGCs, in vitro. We observed that a small subset of late retinal progenitors, enriched from E18, PN1, or $\mathrm{PN} 3$ retinas, possesses the capacity to generate cells that display RGC phenotypes. These progenitors, like their early retinal counterparts, respond favorably to cues present at early histogenesis. These cues, yet unknown, may play a critical role in promoting the differentiation of RGCs in vivo. This notion is supported by the fact that they are evolutionarily conserved, because cells removed from the early stage of retinal histogenesis, either from chick or rat, have a similar RGC-promoting effect on late retinal progenitors in vitro. Remarkably, cues emanating from these cells in the early stage of histogenesis have a potent inhibitory effect on the differentiation of late-born neurons. A similar rod-inhibitory influence of embryonic retina, partly mediated through the CNTF family of cytokines, has been reported recently (Belliveau et al., 2000). These observations suggest that, although the environment in the early stages of histogenesis is naturally geared toward promoting the specification of earlyborn neurons, it also ensures that premature differentiation of late-born neurons does not take place. Whereas cues present in the early stages of histogenesis promote RGC differentiation, those present in the late stages have a negative influence on the differentiation of progenitors along the RGC lineage. Waid and McLoon (1998) have identified a factor secreted by matured chick RGCs that actively prevents progenitors from choosing the RGC fate. It is therefore likely that the late retinal progenitors, fated to generate late-born neurons, are constrained from giving 


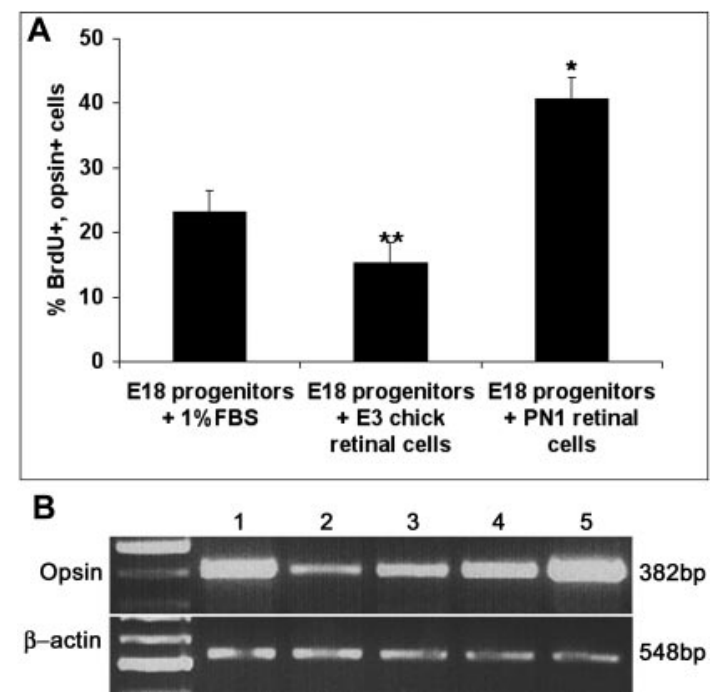

Figure 6. Factor(s) elaborated by cells representing the early stage of retinal histogenesis inhibit differentiation of late-born neurons. BrdU-tagged late retinal progenitors were cultured in the presence of $1 \%$ FBS, E3 chick retinal cells, and PN1 rat retinal cells for 5-7d, and examined for the expression of opsin, a rod photoreceptor marker. The proportion of BrdU-tagged progenitors expressing opsin decreased significantly in the presence of E3 chick retinal cells compared with those in the presence of $1 \% \mathrm{FBS}\left({ }^{* *} p<0.01\right)(A)$. In contrast, the proportion of opsin-positive cells increased significantly when progenitors were cultured with PN1 retinal cells that have been shown to elaborate rod-promoting factors $\left({ }^{*} p<0.01\right)(A)$. Values are means \pm SEM of four to six separate observations, as assessed by one-way ANOVA. RT-PCR analysis of transcripts corresponding to opsin was performed on late retinal progenitors cultured with different embryonic cells across the membrane $(B)$. The analysis showed that, compared with FBS control (lane 1), the level of opsin transcripts decreased in the presence of $E 3$ chick retinal cells (lane 3), E3 chick cerebral cortex (lane 2), and PN1 cerebral cortex cells (lane 4), and increased in the presence of PN1 retinal cells (lane 5).

rise to RGCs under the influence of such factors (see below). The presence of inhibitory factors may also explain why the differentiation of enriched late retinal progenitors into RGCs is severely compromised when transplanted into the retina.

The differentiation of late retinal progenitors into RGCs involves the recruitment of mechanisms that are used during the normal development of RGCs. This notion is supported by the following observations. First, Notch signaling, which has been shown to play a critical role in both temporal and spatial specification of RGCs (Ahmad et al., 1995, 1997; Austin et al., 1995), is activated in late retinal progenitors when cocultured with cells from an early stage of retinal histogenesis. The levels of components of Notch signaling, the Notch1 receptor and the downstream effector Hes1, are increased during RGC differentiation. However, like that observed in vivo, there was a relative difference in the levels of Notch signaling between progenitors and committed precursor populations, as suggested by the difference in the levels of transcripts corresponding to components of Notch signaling in progenitor population (SP cells) and the precursor population (NSP cells). This difference in Notch signaling between progenitors and RGC precursors may accentuate the phenotypic differences between the two (Ahmad et al., 1997). It is likely that proneural genes are upregulated in response to a decrease in Notch signaling in RGC precursors, one of the effects of which is an increase in the levels of Deltal (Kunisch et al., 1994; Heitzler et al., 1996). These precursor cells that overexpress Delta1 may accentuate Notch signaling in the neighboring progenitors, thereby amplifying initial minor differences between the two cell populations; cells in which Notch signaling is relatively weak differentiate as RGCs, whereas cells in which Notch signaling is relatively

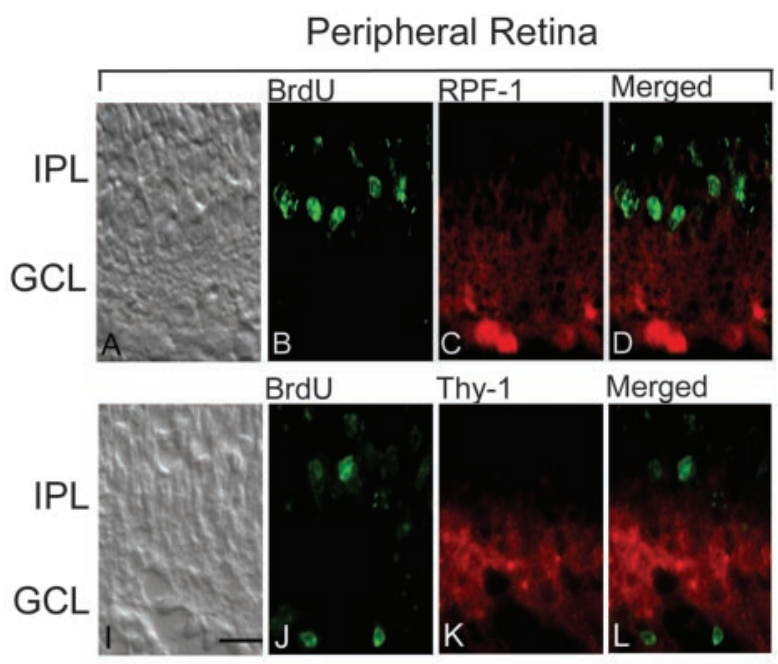

Central Retina
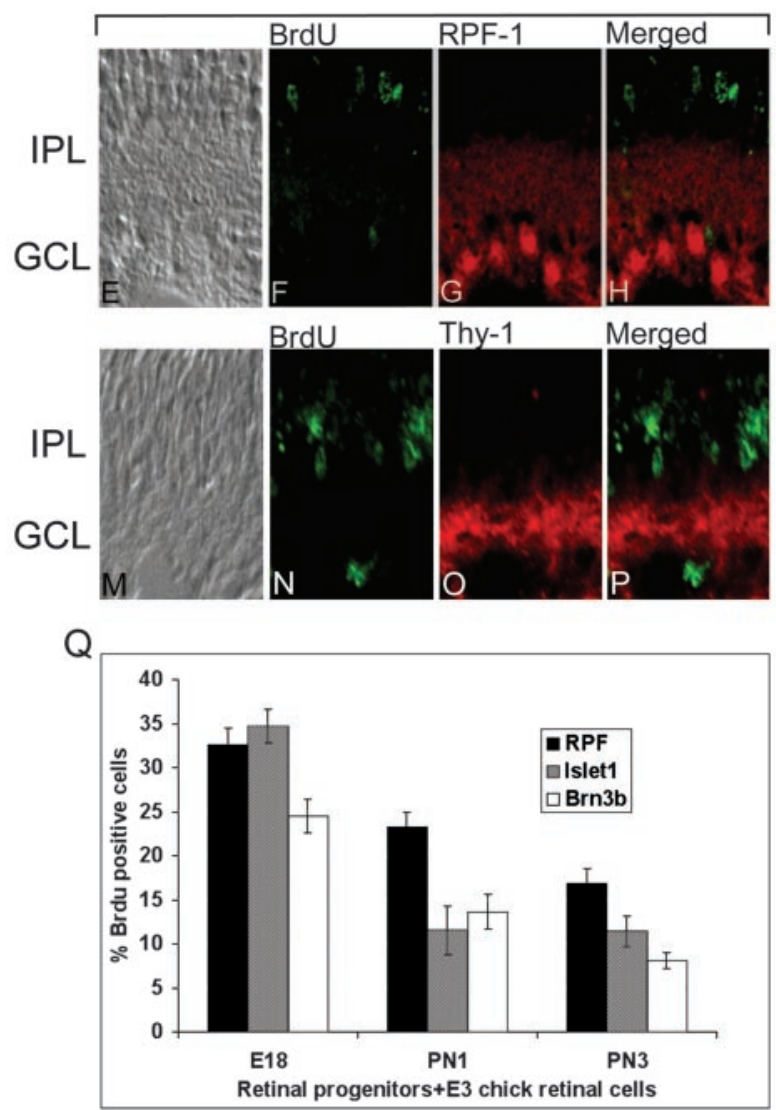

Figure 7. In vitro-generated $\mathrm{RGCS}$ are not derived from residual early retinal progenitors. Retinas of PN1 pups of pregnant rats, treated with BrdU at the gestation age of E18, were processed for immunocytochemical analysis using anti-BrdU antibodies and antibodies against RGC markers RPF1 $(A-H)$ and Thy $1(I-P)$. BrdU-positive cells can be observed, but none of those coexpressed RPF1 or Thy1, in either the peripheral or central retina. Coculture of E18, PN1, and PN3 retinal progenitors with E3 chick retinal cells shows a progressive decrease in the cells expressing RGC-specific markers RPF1, Islet1, and Brn3b with each subsequent time point ( $Q$ ). Values are means \pm SEM of four to six separate observations, as assessed by one-way ANOVA. Scale bar, $50 \mu \mathrm{m}$. IPL, Inner plexiform layer; GCL, ganglion cell layer.

strong remain uncommitted retinal progenitors (Tanabe and Jessell, 1996; Ahmad et al., 1997; Bertrand et al., 2002). The increase in the levels of Delta1 mRNA in SP cells, although it appears contradictory in the presence of enhanced Notch signaling, is 
A
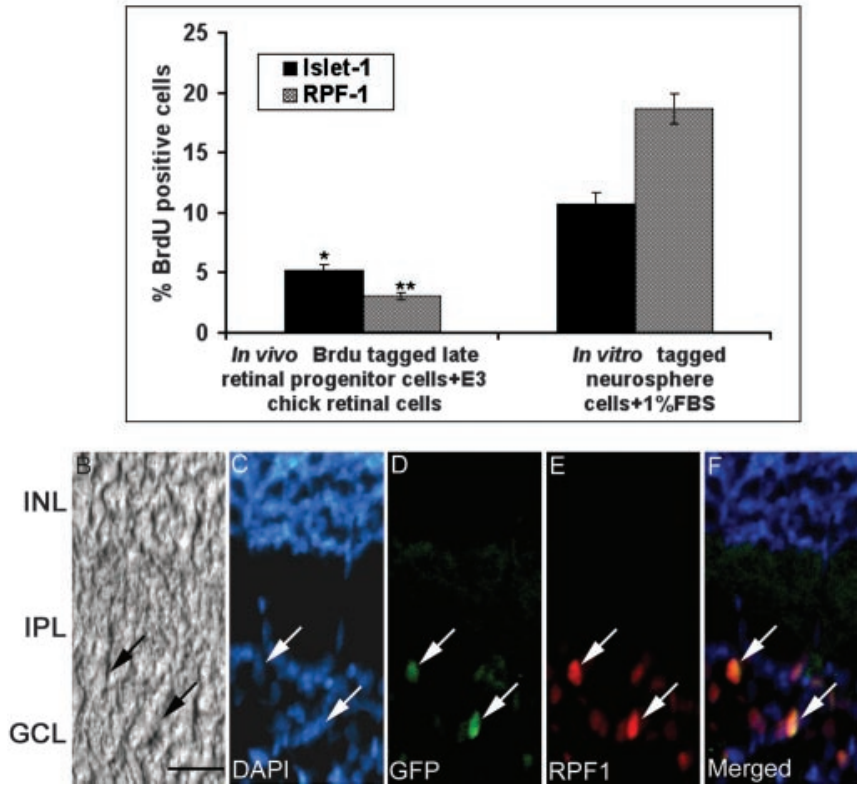

Figure 8. Late retinal progenitors are constrained from differentiating into RGC in vivo. Late retinal progenitors, tagged with BrdU in vivo at E18, were harvested and cultured immediately with E3 chick retinal cells for 5 d. Late retinal progenitors, tagged with BrdU in vitro after $7 \mathrm{~d}$ in the presence of mitogens, were cultured in the presence of $1 \% \mathrm{FBS}$ for $5 \mathrm{~d}$. At the end of culture, the proportion of BrdU-positive cells expressing Islet1 and RPF1 were examined $(A)$. The proportion of in vivo BrdU-tagged cells expressing RPF1 and Islet1 was significantly lower than that of in vitro BrdU-tagged cells expressing RGC-specific markers ( ${ }^{*}|s|$ let1, $p<0.05$; ${ }^{* *} \mathrm{RPF} 1, p<$ 0.001 ). Values are means \pm SEM of four to six separate observations, as assessed by Student's $t$ test. GFP-expressing late retinal progenitors were transplanted intravitreally into the eyes of PN10 transgenic (P23H) rats. GFP-positive cells integrated into the host laminar structure of the retina and expressed RPF1, suggesting their differentiation along RGC lineage ( $B-F$ ). Arrows indicate transplanted GFP + RPF1-positive cells. Scale bar, $50 \mu \mathrm{m}$. DAPI, 4', $6^{\prime}$-Diamidino-2phenylindole; GCL, ganglion cell layer; INL, inner nuclear layer; IPL, inner plexiform layer.

likely in response to a possible parallel signaling used by progenitors to ensure their proliferation and noncommitted state. One such signaling may involve the EGF receptor (Ahmad et al., 1998a). It has been shown recently that the activation of the RasMAPK (mitogen-activated protein kinase) pathway, a downstream component of signaling through the EGF receptor, leads to upregulation of Delta in the progenitor population in Drosophila (Carmena et al., 2002). It is likely that Deltal expressed by the progenitor population further reinforces Notch signaling (Karanu et al., 2001). Second, the changes in the levels of Notch signaling during RGC differentiation were accompanied by an increase in the levels of a regulator of RGCs, Ath5, and its target, Brn3b. Evidence has emerged from a variety of experimental approaches that Ath5 is a key regulator of RGC differentiation (Vetter and Brown, 2001). Expression of Ath5 coincides with RGC genesis (Kanekar et al., 1997; Brown et al., 1998; MatterSadzinski et al., 2001), and experiments on both the loss and gain of Ath 5 function have demonstrated that Ath 5 is required for the generation of RGC genesis (Kanekar et al., 1997; Brown et al., 2001; Wang et al., 2001). Evidence suggests that one of the targets of Ath5 in RGC precursors is Brn3b, a known regulator of RGC differentiation and survival (Xiang et al., 1993; Gan et al., 1999). Therefore, our observations suggest that a subset of late retinal progenitors use both Notch signaling- and Ath5-related cascade reactions for differentiation along RGC lineage. Although the exact nature of cooperation between the two mechanisms during RGC differentiation is not known, a recent study of cell fate spec-

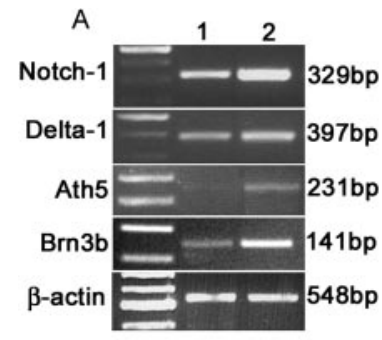

B
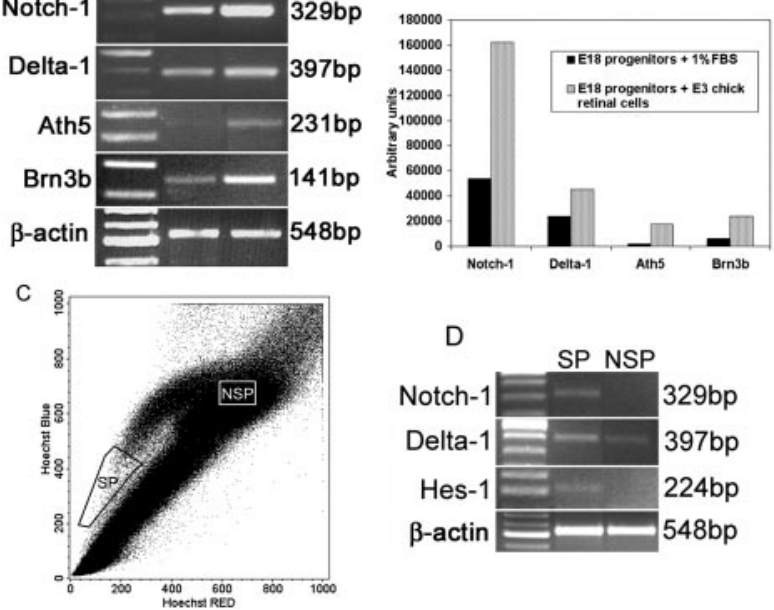

Figure 9. Differentiation of late retinal progenitors into RGC involves Notch-1 receptor and bHLH transcription factor Ath5. RT-PCR analysis was performed on late retinal progenitors cultured in the presence of $1 \% \mathrm{FBS}$ and $\mathrm{E} 3$ chick retinal cells to examine the levels of specific transcripts. The levels of transcripts corresponding to Notch-1, Delta-1, Ath5, and Brn3b were increased in coculture condition (lane 2) in comparison with that in 1\% FBS control (lane 1) $(A$, $B$ ). Hoechst dye efflux assay was used to separate progenitor and precursor populations as SP and NSP, respectively (C). RT-PCR analysis performed on these two populations showed that levels of transcripts corresponding to Notch-1, Hes1, and Delta-1 were relatively higher in SP cells than in NSP cells $(D)$.

ification in the ciliary margin zone of Xenopus retina shed light on their interactions; activation of Notch signaling promotes cell cycle exit that potentiates the RGC determination activity of Ath5 (Ohnuma et al., 2002).

An interesting question that emerges from our study is how a small subset of late retinal progenitors maintains its competence to differentiate into early-born neurons. This can be explained on the presumption that the developmental change in the competency of retinal progenitors is not absolute. As development progresses, the progenitors acquire the ability to respond more favorably to cues that promote the generation of late-born neurons than to those conducive for giving rise to early-born neurons. This premise presupposes that the late retinal progenitors may have a residual ability to generate RGCs, but odds are heavily against such specification as they find themselves inundated with cues for the generation of late-born neurons and inhibitory factors for RGC differentiation, elaborated by early-born neurons such as the RGCs (Waid and McLoon, 1998). Enrichment of late retinal progenitors in vitro is likely to dilute these negative environmental influences, thus removing the impediments toward their differentiation into RGCs. A similar selection of alternate fates has been observed in the case of ectodermal stem cells/progenitors that decide to differentiate along neural instead of epidermal lineage when epidermalizing factors, BMPs (bone morphogenetic proteins), are diluted in vitro (Wilson and Hemmati-Brivanlou, 1999; Zhao et al., 2002). However, the question remains why only a small subset of late retinal progenitors divert from their normal fate. This may be attributable to the fact that a large proportion of late retinal progenitors from E18 onward are already committed along the photoreceptor lineage (i.e., rod precursors), because rods constitute $>70 \%$ of the retinal cell population (Young, 1985; Ahmad et al., 1999). Therefore, only a small proportion of dividing cells may represent the true progenitor population at E18 onward, and a subset of these cells is the one that changes to RGC fate. 
Additional evidence that these cells belong to the late progenitor population and may not represent a special, more plastic subpopulation set aside during early histogenesis comes from the observation that their number decreases progressively as histogenesis proceeds toward completion. As late histogenesis continues, cells are likely to be drawn from this subpopulation to generate late-born neurons and Müller glia, thereby progressively depleting their number and, hence, a progressive decrease in the number of RGCs born under the influence of E3 chick retinal cells. Besides, even at the late stage of differentiation, precursors that are fated to become rods are not irreversibly committed to the photoreceptor lineage. This notion is supported by the observation that prospective rods, even when they become postmitotic, could be respecified by epigenetic factor CNTF along a completely different lineage to give rise to bipolar cells (Ezzeddine et al., 1997). Together, our observations suggest that late retinal progenitors may not be irreversibly committed to give rise to late-born neurons. The repertoire of genes expressed by them at that stage makes them partial toward cues that promote the specification of late-born neurons. Their residual potential to give rise to early-born neurons is likely to be counterbalanced by inhibitory factors elaborated by mature early-born neurons. Thus, late retinal progenitors may appear irreversibly fated under constraints dictated by epigenetic cues.

\section{References}

Ahmad I (1995) Mash-1 is expressed during ROD photoreceptor differentiation and binds an E-box, E(opsin)- 1 in the rat opsingene. Brain Res Dev Brain Res 90:184-189.

Ahmad I, Zaqouras P, Artavanis-Tsakonas S (1995) Involvement of Notch-1 in mammalian retinal neurogenesis: association of Notch-1 activity with both immature and terminally differentiated cells. Mech Dev 53:73-85.

Ahmad I, Dooley CM, Polk DL (1997) Delta-1 is a regulator of neurogenesis in the vertebrate retina. Dev Biol 185:92-103.

Ahmad I, Dooley CM, Afiat S (1998a) Involvement of Mash1 in EGFmediated regulation of differentiation in the vertebrate retina. Dev Biol 194:86-98.

Ahmad I, Acharya HR, Rogers JA, Shibata A, Smithgall TE, Dooley CM (1998b) The role of NeuroD as a differentiation factor in the mammalian retina. J Mol Neurosci 11:165-178.

Ahmad I, Dooley CM, Thoreson WB, Rogers JA, Afiat S (1999) In vitro analysis of a mammalian retinal progenitor that gives rise to neurons and glia. Brain Res 831:1-10.

Altshuler D, Cepko C (1992) A temporally regulated, diffusible activity is required for rod photoreceptor development in vitro. Development 114:947-957.

Altshuler D, Lo Turco JJ, Rush J, Cepko C (1993) Taurine promotes the differentiation of a vertebrate retinal cell type in vitro. Development 119:1317-1328.

Anchan RM, Reh TA, Angello J, Balliet A, Walker M (1991) EGF and TGF- $\alpha$ stimulate retinal neuroepithelial cell proliferation in vitro. Neuron 6:923-936.

Austin CP, Feldman DE, Ida Jr JA, Cepko CL (1995) Vertebrate retinal ganglion cells are selected from competent progenitors by the action of Notch. Development 121:3637-3650.

Bae S, Bessho Y, Hojo M, Kageyama R (2000) The bHLH gene Hes6, an inhibitor of Hes1, promotes neuronal differentiation. Development 127:2933-2943.

Belliveau MJ, Cepko CL (1999) Extrinsic and intrinsic factors control the genesis of amacrine and cone cells in the rat retina. Development 126:555-566.

Belliveau MJ, Young TL, Cepko CL (2000) Late retinal progenitor cells show intrinsic limitations in the production of cell types and the kinetics of opsin synthesis. J Neurosci 20:2247-2254.

Bertrand N, Castro DS, Guillemot F (2002) Proneural genes and the specification of neural cell types. Nat Rev Neurosci 3:517-530.

Bhattacharya S, Jackson JD, Das AV, Thoreson WB, Kuszynski C, James J, Joshi S, Ahamd I (2003) Direct identification and enrichment of retinal stem cells/progenitors using Hoechst dye efflux assay. Invest Ophthalmol Vis Sci 44:2764-2773.

Brown NL, Kanekar S, Vetter ML, Tucker PK, Gemza DL, Glaser T (1998) Math5 encodes a murine basic helix-loop-helix transcription factor expressed during early stages of retinal neurogenesis. Development 125:4821-4833.

Brown NL, Patel S, Brzezinski J, Glaser T (2001) Math5 is required for retinal ganglion cell and optic nerve formation. Development 128:2497-2508.

Carmena A, Buff E, Halfon MS, Gisselbrecht S, Jimenez F, Baylies MK, Michelson AM (2002) Reciprocal regulatory interactions between the Notch and Ras signaling pathways in the Drosophila embryonic mesoderm. Dev Biol 244:226-242.

Cepko CL (1999) The roles of intrinsic and extrinsic cues and bHLH genes in the determination of retinal cell fates. Curr Opin Neurobiol 9:37-46.

Chacko DM, Das AV, Zhao X, James J, Bhattacharya S, Ahmad I (2003) Transplantation of ocular stem cells: the role of injury in incorporation and differentiation of grafted cells in the retina. Vision Res 43:937-946.

Christie GA (1964) Devolopment stages in somite and post-somite rat embryos. Based on external appearance, and including some features of the macroscopic development of the oral cavity. J Morphol 114:263-286.

Dorsky RI, Rapaport DH, Harris WA (1995) Xotch inhibits cell differentiation in the Xenopus retina. Neuron 14:487-496.

Dorsky RI, Chang WS, Rapaport DH, Harris WA (1997) Regulation of neuronal diversity in the Xenopus retina by Delta signalling. Nature 385:67-70.

Ezzeddine ZD, Yang X, DeChiara T, Yancopoulos G, Cepko CL (1997) Postmitotic cells fated to become rod photoreceptors can be respecified by CNTF treatment of the retina. Development 124:1055-1067.

Frantz GD, McConnell SK (1996) Restriction of late cerebral cortical progenitors to an upper-layer fate. Neuron 17:55-61.

Gan L, Xiang M, Zhou L, Wagner DS, Klein WH, Nathans J (1996) POU domain factor Brn-3b is required for the development of a large set of retinal ganglion cells. Proc Natl Acad Sci USA 93:3920-3925.

Gan L, Wang SW, Huang Z, Klein WH (1999) POU domain factor Brn-3b is essential for retinal ganglion cell differentiation and survival but not for initial cell fate specification. Dev Biol 210:469-480.

Hamburger V, Hamilton HL (1951) A series of normal stages in the development of the chick embryo. J Morphol 88:49-92.

Harris WA, Messersmith SL (1992) Two cellular inductions involved in photoreceptor determination in the Xenopus retina. Neuron 9:357-372.

Heitzler P, Bourouis M, Ruel L, Carteret C, Simpson P (1996) Genes of the Enhancer of split and achaete-scute complexes are required for a regulatory loop between Notch and Delta during lateral signalling in Drosophila. Development 122:161-171.

Hicks D, Courtois Y (1992) Fibroblast growth factor stimulates photoreceptor differentiation in vitro. J Neurosci 12:2022-2033.

Holt CE, Bertsch TW, Ellis HM, Harris WA (1988) Cellular determination in the Xenopus retina is independent of lineage and birth date. Neuron $1: 15-26$.

Jasoni CL, Reh TA (1996) Temporal and spatial pattern of MASH-1 expression in the developing rat retina demonstrates progenitor cell heterogeneity. J Comp Neurol 369:319-327.

Kageyama R, Ishibashi M, Takebayashi K, Tomita K (1997) bHLH transcription factors and mammalian neuronal differentiation. Int J Biochem Cell Biol 29:1389-1399.

Kahn AJ (1974) An autoradiographic analysis of the time of appearance of neurons in the developing chick neural retina. Dev Biol 38:30-40.

Kanekar S, Perron M, Dorsky R, Harris WA, Jan LY, Jan YN, Vetter ML (1997) Xath5 participates in a network of bHLH genes in the developing Xenopus retina. Neuron 19:981-994.

Karanu FN, Murdoch B, Miyabayashi T, Ohno M, Koremoto M, Gallacher L, Wu D, Itoh A, Sakano S, Bhatia M (2001) Human homologues of Delta- 1 and Delta-4 function as mitogenic regulators of primitive human hematopoietic cells. Blood 97:1960-1967.

Kelley MW, Turner JK, Reh TA (1994) Retinoic acid promotes differentiation of photoreceptors in vitro. Development 120:2091-2102.

Kirsch M, Fuhrmann S, Wiese A, Hofmann HD (1996) CNTF exerts opposite effects on in vitro development of rat and chick photoreceptors. NeuroReport 7:697-700.

Kunisch M, Haenlin M, Campos-Ortega JA (1994) Lateral inhibition mediated by the Drosophila neurogenic gene Delta is enhanced by proneural proteins. Proc Natl Acad Sci USA 91:10139-10143. 
LaVail MM, Faktorovich EG, Hepler JM, Pearson KL, Yasumura D, Matthes MT, Steinberg RH (1991) Basic fibroblast growth factor protects photoreceptors from light-induced degeneration in albino rats. Ann NY Acad Sci 638:341-347.

Lewin AS, Drenser KA, Hauswirth WW, Nishikawa S, Yasumura D, Flannery JG, LaVail MM (1998) Ribozyme rescue of photoreceptor cells in a transgenic rat model of autosomal dominant retinitis pigmentosa. Nat Med 4:967-971.

Levine EM, Roelink H, Turner J, Reh TA (1997) Sonic hedgehog promotes rod photoreceptor differentiation in mammalian retinal cells in vitro. J Neurosci 17:6277-6288.

Lillien L, Cepko C (1992) Control of proliferation in the retina: temporal changes in responsiveness to FGF and TGF $\alpha$. Development 115:253-266.

Matter-Sadzinski L, Matter JM, Ong MT, Hernandez J, Ballivet M (2001) Specification of neurotransmitter receptor identity in developing retina: the chick ATH5 promoter integrates the positive and negative effects of several bHLH proteins. Development 128:217-231.

Morrow EM, Belliveau MJ, Cepko CL (1998) Two phases of rod photoreceptor differentiation during rat retinal development. J Neurosci 18:3738-3748.

Morrow EM, Furukawa T, Lee JE, Cepko CL (1999) NeuroD regulates multiple functions in the developing neural retina in rodent. Development 126:23-36.

Negishi K, Teranishi T, Kato S (1982) New dopaminergic and indoleamineaccumulating cells in the growth zone of goldfish retinas after neurotoxic destruction. Science 216:747-749.

Neophytou C, Vernallis AB, Smith A, Raff MC (1997) Muller-cell-derived leukaemia inhibitory factor arrests rod photoreceptor differentiation at a postmitotic pre-rod stage of development. Development 124:2345-2354.

Ohnuma S, Hopper S, Wang KC, Philpott A, Harris WA (2002) Coordinating retinal histogenesis: early cell cycle exit enhances early cell fate determination in the Xenopus retina. Development 129:2435-2446.

Okabe M, Ikawa M, Kominami K, Nakanishi T, Nishimune Y (1997) "Green mice" as a source of ubiquitous green cells. FEBS Lett 407:313-319.

O'Rourke NA, Sullivan DP, Kaznowski CE, Jacobs AA, McConnell SK (1995) Tangential migration of neurons in the developing cerebral cortex. Development 121:2165-2176.

Prada C, Puga J, Perez-Mendez L, Lopez R, Ramirez G (1991) Spatial and temporal patterns of neurogenesis in the chick retina. Eur J Neurosci 3:559-569.

Rachel RA, Dolen G, Hayes NL, Lu A, Erskine L, Nowakowski RS, Mason CA (2002) Spatiotemporal features of early neuronogenesis differ in wildtype and albino mouse retina. J Neurosci 22:4249-4263.

Rapaport DH, Patheal SL, Harris WA (2001) Cellular competence plays a role in photoreceptor differentiation in the developing Xenopus retina. J Neurobiol 49:129-141.

Reese BE, Colello RJ (1992) Neurogenesis in the retinal ganglion cell layer of the rat. Neuroscience 46:419-429.

Reh TA (1992) Cellular interactions determine neuronal phenotypes in rodent retinal cultures. J Neurobiol 23:1067-1083.

Reh TA, Tully T (1986) Regulation of tyrosine hydroxylase-containing amacrine cell number in larval frog retina. Dev Biol 114:463-469.
Robinson SR (1991) Neuroanatomy of the visual pathways and their development. In: Vision and visual dysfunction, Vol 3 (Dreher B, Robinson SR eds), pp 59-128. London: MacMillan.

Roztocil T, Matter-Sadzinski L, Alliod C, Ballivet M, Matter JM (1997) NeuroM, a neural helix-loop-helix transcription factor, defines a new transition stage in neurogenesis. Development 124:3263-3272.

Sidman RL (1961) Histogenesis of mouse retina studied with thymidine $\left[{ }^{3} \mathrm{H}\right]$. In: The structure of the eye (Smelser G, ed), pp 487-506. New York: Academic.

Sommer L, Ma Q, Anderson DJ (1996) neurogenins, a novel family of atonalrelated bHLH transcription factors, are putative mammalian neuronal determination genes that reveal progenitor cell heterogeneity in the developing CNS and PNS. Mol Cell Neurosci 8:221-241.

Tanabe Y, Jessell TM (1996) Diversity and pattern in the developing spinal cord. Science 274:1115-1123.

Tsuda H, Takebayashi K, Nakanishi S, Kageyama R (1998) Structure and promoter analysis of Math3 gene, a mouse homolog of Drosophila proneural gene atonal. Neural-specific expression by dual promoter elements. J Biol Chem 273:6327-6333.

Turner DL, Cepko CL (1987) A common progenitor for neurons and glia persists in rat retina late in development. Nature 328:131-136.

Turner DL, Snyder EY, Cepko CL (1990) Lineage-independent determination of cell type in the embryonic mouse retina. Neuron 4:833-845.

Vetter ML, Brown NL (2001) The role of basic helix-loop-helix genes in vertebrate retinogenesis. Semin Cell Dev Biol 12:491-498.

Waid DK, McLoon SC (1998) Ganglion cells influence the fate of dividing retinal cells in culture. Development 125:1059-1066.

Wang SW, Kim BS, Ding K, Wang H, Sun D, Johnson RL, Klein WH, Gan L (2001) Requirement for math 5 in the development of retinal ganglion cells. Genes Dev 15:24-29.

Watanabe T, Raff MC (1990) Rod photoreceptor development in vitro: intrinsic properties of proliferating neuroepithelial cells change as development proceeds in the rat retina. Neuron 4:461-467.

Watanabe T, Raff MC (1992) Diffusible rod-promoting signals in the developing rat retina. Development 114:899-906

Wetts R, Fraser SE (1988) Multipotent precursors can give rise to all major cell types of the frog retina. Science 239:1142-1145.

Wilson PA, Hemmati-Brivanlou A (1999) Induction of epidermis and inhibition of neural fate by Bmp-4. Nature 376:331-333.

Xiang M, Zhou L, Peng YW, Eddy RL, Shows TB, Nathans J (1993) Brn-3b: a POU domain gene expressed in a subset of retinal ganglion cells. Neuron 11:689-701.

Young RW (1985) Cell differentiation in the retina of the mouse. Anat Rec 212:199-205.

Zhang XM, Yang XJ (2001) Temporal and spatial effects of Sonic hedgehog signaling in chick eye morphogenesis. Dev Biol 233:271-290.

Zhao X, Das AV, Thoreson WB, James J, Wattnem TE, Rodriguez-Sierra J, Ahmad I (2002) Adult corneal limbal epithelium: a model for studying neural potential of non-neural stem cells/progenitors. Dev Biol 250: 317-331.

Zhou H, Yoshioka T, Nathans J (1996) Retina-derived POU-domain factor-1: a complex POU-domain gene implicated in the development of retinal ganglion and amacrine cells. J Neurosci 16:2261-2274. 